\title{
PALADINO, Mariana; ALMEIDA, Nina Paiva. Entre a Diversidade e a desigualdade: uma análise das políticas públicas para a educação escolar indígena no Brasil dos governos Lula. Rio de Janeiro: Contra Capa Livraria; LACED/Museu Nacional/UFRJ, 2012. 152p.
}

Éder da Silva Novak*

UEM/UFGD

\author{
Keros Gustavo Mileski** \\ UEM/FACINOR
}

Os estudos e discussões sobre a educação escolar indígena vêm se ampliando nas últimas décadas, juntamente com uma mudança de concepção no entendimento desta, sobretudo a partir da Constituição de 1988 e o aparato legal dela decorrente. Nesse ínterim, a questão da diversidade vem ganhando espaço e com ela a discussão a respeito da educação para diversos grupos étnicos e sociais, entre eles as populações indígenas. A construção de uma escola intercultural e bilíngue é um processo que vem ganhando espaço nas agendas governamentais do país, como pode ser destacado nos dois governos do Presidente Luiz Inácio Lula da Silva (2003-2010), assunto abordado no livro aqui resenhado.

No contexto de ampliação dos trabalhos sobre a temática, a obra apresenta-se como uma proposta de discussão em torno das políticas educacionais para a diversidade, sobretudo os programas e ações da Secretaria de Educação Continuada, Alfabetização, Diversidade e Inclusão do Ministério da Educação (SECADI/MEC) para os indígenas durante os governos do presidente Lula. O livro tem como objetivo informar sobre as ideias centrais que orientam as políticas de ações afirmativas executadas nas últimas décadas, bem como suscitar questões para pesquisas sobre a temática, com ênfase nas populações indígenas, disponibilizando assim informações dos programas, ações e fontes de financiamento do MEC.

As informações contidas na obra são oriundas de documentos do MEC, Funai e fontes oficiais que, para as autoras, evidenciam a ausência de "um acompanhamento eficaz das ações empreendidas, bem como a inexistência de sistematização adequada dos dados já coletados” (PALADINO; ALMEIDA, 2012, p. 10). Utilizam também, como fonte,

* Mestre em História. edernovak@bol.com.br

** Mestre em Educação. kerosgustavo@gmail. com 
entrevistas com gestores da educação escolar indígena em nível federal e de informações obtidas em eventos, bem como os estudos das autoras em âmbito de pós-graduação vinculados ao projeto "Trilhas do Conhecimento. O ensino superior indígena no Brasil”, coordenado por Antonio Carlos de Souza Lima que, no nosso entendimento, é um dos principais polos de discussão sobre as políticas voltadas para as populações indígenas, entre elas as ações voltadas para o ensino superior.

Mariana Paladino é doutora em Antropologia pelo Programa de Pósgraduação em Antropologia Social (PPGAS/MN/UFRJ), pesquisadora associada ao Laboratório de Pesquisas em Etnicidade, Cultura e Desenvolvimento (LACED), Departamento de Antropologia, Museu Nacional e desenvolve pesquisas na área de educação, interculturalidade, ações afirmativas, políticas indigenistas e relações interétnicas. Nina Paiva é doutoranda em Antropologia Social no PPGAS/MN/UFRJ. É servidora da Fundação Nacional do Índio (Funai), no cargo de Indigenista Especializado, desde 2010. As autoras são portanto importantes nomes no cenário nacional sobre a questão das políticas educacionais voltadas para as populações indígenas.

O livro divide-se em três partes. A primeira intitula-se “A luta pela valorização da diversidade no Brasil”, composta por seis capítulos cujo objetivo é trazer as lutas e conquistas dos movimentos sociais, sobretudo do movimento indígena no período pós-redemocratização do país, focando para isso os marcos legais e os conceitos que orientam a política da diversidade, da interculturalidade e das ações afirmativas. A segunda parte, "Políticas públicas voltadas ao reconhecimento da diversidade”, traz cinco capítulos que discutem questões como a criação e ações da SECAD, além das ações em outras instâncias desenvolvidas durante o governo Lula para a Educação Escolar Indígena. Na terceira parte, discutem o "Ensino superior”, a partir de cinco capítulos que abordam elementos como as políticas de acesso e permanência a este nível de ensino, bem como os seus desafios.

No primeiro capítulo, intitulado "Diversidade e interculturalidade”, mostram que estes termos são recorrentes nas reivindicações dos movimentos sociais e orientadores de políticas públicas, entre elas a Educação Escolar Indígena, porém são pouco problematizados no que se refere aos seus sentidos e formas de utilização. A interculturalidade é um termo utilizado desde a década de 1970 em contraposição ao modelo de políticas para tratar a questão da diversidade a partir do viés assimilacionista e integracionista. Segundo as autoras, o termo pode ser utilizado na área da educação, visto que para elas há várias formas de entendimento do conceito, atreladas a diferentes posicionamentos e projetos políticos, éticos e filosóficos, evidenciando como este foi utilizado pela SECAD no que tange à Educação Escolar Indígena. 
No segundo capítulo, “Ações Afirmativas”, mostram que o termo chega ao Brasil com uma variedade de sentidos. Remontam a sua origem nos EUA, na década de 1960, período de luta, sobretudo, do movimento negro pelos direitos civis. Desde então, sua utilização assumiu vários públicos e diferentes formas, sendo muito discutida na área da educação. No Brasil, tem recebido um tratamento variado, com posicionamentos polarizados entre os contrários que defendem políticas universalistas e os seus defensores que a veem como uma política importante voltada a grupos historicamente discriminados. Por fim, problematizam a forma como esta vem sendo implementada para as populações indígenas, sem atender suas especificidades.

O terceiro capítulo, intitulado “Avanços nas políticas de reconhecimento da diversidade no Brasil”, aborda as ações e projetos de diversidade desenvolvidos no final dos anos 1990, através da parceria entre o governo federal e os organismos internacionais. Sobretudo, a partir da Constituição de 1988 os movimentos sociais vêm reivindicando do governo federal ações relacionadas às questões de gênero, raça e etnia. Não se verifica até o final dos anos 1990 ações voltadas a melhoria de acesso e permanência dos negros no ensino superior. Discutem outros marcos importantes como a preparação do Brasil para a participação na Conferência Internacional contra o Racismo, a Xenofobia e a Intolerância Correlata, realizada em Durbam, África do Sul, em 2001. Destacam ainda o Programa Diversidade na Universidade, de 2002 e a atuação da Fundação Ford a partir de dois programas: "Programa Internacional de Bolsas de Estudos” e "Programa Caminhos para a Educação Superior”.

As discussões do quarto capítulo, nominado "Educação Escolar e Povos Indígenas”, fazem referência à educação escolar destinada aos povos indígenas ao longo do século XX. Nesse sentido, chamam atenção para o fato de que ela foi realizada com foco na atuação do Serviço de Proteção ao Índio (SPI), de 1910 a 1967, e posteriormente com a atuação da FUNAI, de 1967 até 1991, quando a responsabilidade da educação escolar indígena é transferida para o MEC. Abordam a atuação de organizações não governamentais nas décadas de 1970 e 1980, em busca de uma educação diferenciada, com materiais bilíngues, capacitação de professores e magistério e a criação na década de 1980 de um movimento de professores indígenas nos estados de Amazonas, Roraima e Acre. Terminam o capítulo mostrando que a Constituição de 1988 é um marco no fim da visão integracionista e na garantia de direitos específicos aos indígenas.

O quinto capítulo, "Direitos indígenas na Constituição Federal de 1988 e seus desdobramentos nas políticas de educação”, mostra como se cria a partir da Constituição um novo paradigma na relação entre Estado e povos indígenas na área da educação, marcada pela proposta de uma educação bilíngue, específica, diferenciada e intercultural. Em 1991, 
com a transferência da responsabilidade da Educação Escolar Indígena da FUNAI para o MEC, a execução desta ficou a cargo das Secretarias Estaduais de Educação. No âmbito do MEC foi criada, com a finalidade de acompanhamento, coordenação e apoio, a Coordenação da Educação Escolar Indígena que, em 2001, recebeu o nome de Secretaria da Educação Continuada, Alfabetização, Diversidade e Inclusão (SECADI). Desde então, houve uma ampliação da Educação Escolar Indígena, entre elas o acesso crescente ao ensino superior, a partir de 2001, em cursos regulares em algumas IES e nas "Licenciaturas Interculturais".

O capítulo seis, "Marcos Legais e conceituais da educação escolar indígena”, traz os documentos que normatizam a questão após a Constituição de 1988, que segundo as autoras são oriundos das conquistas realizadas pelo movimento a partir de lutas, mobilizações e apoio da sociedade civil. No entanto, embora esse aparato legal traga avanços, ainda existem muitas questões que precisam ser pensadas com maior cuidado, como, por exemplo, o Ensino Médio e superior.

Estes são os capítulos da primeira parte do texto, que têm um caráter informativo/descritivo, com foco nos marcos legais e nos conceitos presentes nas discussões acerca da diversidade, com ênfase nas ações voltadas para as populações indígenas. Na segunda parte, são abordadas as ações desenvolvidas no governo do presidente Luis Inácio Lula da Silva, no tocante às políticas educacionais para os índios no Brasil.

O capítulo sete, "Políticas de combate à desigualdade e de reconhecimento da diversidade a partir de 2003”, evidencia que já no programa do governo Lula havia uma preocupação com as questões étnicas e raciais que são tratadas em ações como por meio da promulgação da Lei 10.639 de 2003, mesmo ano da criação da Secretaria Especial de Políticas e Promoção da Igualdade Racial (SEPPIR). As ações estenderam-se também para outros ministérios e secretarias visando a abarcar a questão da diversidade existente no país. Na área da educação, foi importante o programa Diversidade na Universidade, do Ministério da Educação. Com relação às ações afirmativas, foi encaminhado ao congresso, em 2006, o Projeto de Lei 73/1999, denominado "Lei de Cotas" que teve sua aprovação apenas em 2012.

“A atuação da SECAD” é título e tema da discussão do oitavo capítulo, no qual são apresentadas as políticas e ações desenvolvidas por essa secretaria. A partir da busca em sites e em publicações do MEC, abordam questões relativas à sua organização, em dois departamentos e cinco coordenações, bem como as áreas temáticas de cada uma delas, destacando a questão da alfabetização e dos eixos da diversidade. Abordam também os programas que visam a atender a educação continuada e o combate às desigualdades na educação. Este capítulo constitui-se, portanto, como uma sistematização dos principais programas e ações desenvolvidas pela SECAD de forma bastante descritiva. 
O nono capítulo intitula-se “As políticas de Educação Escolar Indígena durante o governo Lula” e aborda a temática a partir da Coordenação Geral de Educação Escolar Indígena (CGEEI). Ressalta o aumento durante este governo do orçamento para a pasta, voltado, sobretudo, para a "construção de escolas, apoio à formação de professores em nível de ensinos médio e superior, e ao apoio à publicação de material didático" (PALADINO; ALMDEIDA, 2011, p. 69). Destacam a atuação do FNDE (Fundo Nacional de Desenvolvimento da Educação) e a importância do Fundo Nacional de Desenvolvimento da Educação Básica e Valorização dos Profissionais da Educação (FUNDEB). Com relação às populações indígenas, abordam os objetivos de alguns programas e ações, contribuindo com isso para que se possa ter um panorama geral da Educação Escolar Indígena, pois vislumbra um pouco dos limites e possibilidades abertas a esta durante o governo Lula.

“A Conferência Nacional de Educação Escolar Indígena” é abordada no capítulo dez. As autoras demonstram que sua realização era uma reivindicação das populações indígenas de longo tempo, sendo um importante marco nas discussões das políticas educacionais a eles destinadas. Sua organização ocorreu em três momentos, quais sejam: Conferências nas Comunidades Educativas, que deveriam ocorrer nas escolas indígenas ao longo de 2009; Conferências em 18 regiões do país, nas quais deveriam ser discutidas a realidade da educação escolar indígena e a proposição de ações para sua melhoria. Apresentam seus eixos de discussão, bem como uma síntese do produzido e aprovado por ela, refletindo, com isso, mesmo que de forma sucinta, sobre as principais demandas educacionais das populações indígenas na atualidade.

O capítulo onze, que encerra a segunda parte intitula-se "Oferta de educação escolar indígena entre 2003 e 2010”. Traz dados quantitativos dessa oferta, a partir da comparação de dados dos Censos Escolares do INEP dos últimos dez anos, mostrando a expansão das matrículas nessa modalidade de ensino nos últimos anos, em seus vários níveis, evidenciando além dos avanços os problemas a serem superados.

A terceira parte traz uma discussão relacionada ao recente, mas crescente, tema da educação escolar indígena que é a Educação Superior, denominando-se "Uma discussão sobre o estado atual da educação superior indígena”, composto por cinco capítulos que visam a abarcar as principais demandas e desafios desse nível de ensino para as populações indígenas.

Iniciando a discussão, o capítulo doze, “Considerações iniciais”, destaca que se trata de um tema recente para os indígenas, que não estava presente em suas pautas de reivindicação até o fim da década de 1990, sendo até então uma iniciativa individual ou familiar de poucos indígenas. As autoras apresentam alguns números desse nível de ensino e evidenciam que a demanda por ele vincula-se à necessidade de formação 
de professores visando a atender o quadro normativo da educação escolar indígena e a necessidade de formação de quadros próprios para gestão dos seus territórios e defesa de seus direitos.

No capítulo treze, “As ações voltadas para a formação de professores indígenas em nível superior”, apresentam esta formação como uma demanda decorrente dos dispositivos legais que normatizam a educação brasileira. A principal ação do MEC para a questão foi a criação do Programa de Formação Superior e Licenciaturas Indígenas (PROLIND), através de editais, para o desenvolvimento de licenciaturas interculturais. As autoras apresentam os objetivos, os eixos e as alterações nos três editais oferecidos até o momento - 2012 - pelo programa. Mostram ainda que, mesmo com esses cursos, a formação de professores indígenas ainda é um problema tanto quantitativa, quanto qualitativamente. Problematizam esse formato de graduação de professores, e evidenciam a necessidade de uma maior reflexão a esse respeito.

O capítulo quatorze, intitulado "O acesso de estudantes indígenas nos cursos regulares da educação universitária e sua permanência neles”, mostra que, devido a ausência de uma legislação nacional durante o governo Lula acerca das ações afirmativas nas universidades públicas, esse acesso vem ocorrendo a partir de ações de alguns estados e/ou de algumas universidades. Atualmente, mais de 70 instituições contam com vagas para indígenas a partir de reserva de vagas; vagas suplementares e acréscimo de pontos. O PROUNI também tem contribuído para a ampliação do número de indígenas no ensino superior. Sobre ações afirmativas para os indígenas, a partir de busca em sites de IES, dados do INEP e levantamentos disponíveis sobre o assunto, as autoras apontam 72 instituições públicas com ações para acesso de indígenas. Percebe-se que neste levantamento os dados sobre o Paraná não condizem com a realidade do estado. Segundo o levantamento, o Paraná possui 17 instituições. Na realidade, 10 faculdades mencionadas compõem duas universidades estaduais que agruparam as faculdades isoladas, quais sejam, as Universidade Estadual do Norte do Paraná (UENP) e a Universidade do Estado do Paraná (UNESPAR). Dessa forma, no estado do Paraná, são 7 (sete) instituições públicas que oferecem vagas, mais a Universidade Federal do Paraná. Para encerrar o capítulo, mostram que, embora as políticas de acesso tenham aumentado nos últimos anos, ainda são poucas as ações voltadas a sua permanência e conclusão dos cursos.

O capítulo quinze denomina-se "A atuação da FUNAI e outros órgãos governamentais no apoio à educação superior indígena”. Este mostra que o apoio mencionado teve início na década de 1980, com auxílios financeiros individuais. Com o aumento da demanda, começou-se a firmar acordos de cooperação com algumas universidades e a normatizá-lo. As autoras apresentam uma lista das instituições com as quais a FUNAI tem 
convênios firmados, que,segundo elas, mesmo quantitativamente insuficientes, têm atuação importante devido à falta de uma política para a área vinda do MEC. Abordam a criação pela CAPES do Programa Institucional de Bolsas de Apoio à Docência com foco na diversidade (PIBID/Diversidade), bem como os requisitos para apresentar as propostas e as instituições com projetos aprovados e a demanda por um PIBID voltado para os indígenas. Trazem como ações importantes também a implementação dos Observatórios da Educação Escolar Indígena, em 2009, e o Programa Institucional de Bolsas de Iniciação Científica Ações Afirmativas (Pibic/ Ações Afirmativas).

O capítulo dezesseis, "Breves comentários sobre os debates e os desafios em torno da educação superior indígena”, como o próprio nome sugere, traz os desafios para esse nível de ensino, entre eles a ausência de políticas de permanência voltadas a esses estudantes beneficiados pelas Ações Afirmativas. Salienta ainda a necessidade de avaliação de uma década de aumento de indígenas no ensino superior, bem como apresenta as demandas formuladas pelos estudantes indígenas.

Nas considerações finais, as autoras destacam o percurso descritivo que fizeram no decorrer do livro visando a problematizar as questões acerca da educação escolar indígena e da efetivação de uma educação bilíngue, específica, diferenciada, intercultural e de qualidade. Entendemos que, com isso, o livro cumpre um importante papel de sistematização de ações que podem contribuir com estudos que objetivam aprofundar os avanços e dilemas da educação escolar indígena no país.

Data de submissão: 30/04/2014

Data de aprovação: 18/08/2014 